\title{
Notas sobre o campo das relações internacionais no Brasil no centésimo aniversário da disciplina
}

\author{
Gelson Fonseca Junior - Eduardo Uziel ${ }^{1}$
}

Fool: If thou wert my Fool, nuncle, I'ld have thee beaten for being old before thy time. Lear: How's that?

Fool: Thou shouldst not have been old till thou hadst been wise.

Shakespeare, King Lear, ato I, cena 5

\section{INTRODUÇÃO}

O desenvolvimento acelerado é a característica principal dos estudos de relações internacionais (RI) no Brasil nos últimos 25 anos. Cresceu o número de graduações e pós-graduações, de professores e pesquisadores com mestrado e doutorado, além de se ampliarem as oportunidades de trabalho no governo e na iniciativa privada. Em 2019, havia no Brasil 134 cursos de graduação em relações internacionais (que começaram modestamente com um único curso em 1974) e 30 de pós-graduação na mesma matéria e temas

1 As opiniões expressas pelos autores são pessoais e não necessariamente refletem as do Ministério das Relações Exteriores ou da Fundação Alexandre de Gusmão. afins, ${ }^{2}$ aos quais se somam dezenas de assessorias internacionais nos ministérios, governos estaduais e municipais, em sindicatos, federações de indústria e comércio e no âmbito de outras entidades. Quando se completam os 100 anos do mítico estabelecimento da cadeira de relações internacionais na universidade de Aberystwyth, momento fundador da história da disciplina, o Brasil tem um campo consolidado

2 Dado obtido no sítio http://www.funag.gov. br/ipri/index.php/component/content/article?id=781, em 6/9/19. Estão incluídos no cômputo os cursos de pós-graduação stricto sensu (mestrado e doutorado) em relações internacionais e áreas afins, tais como ciência política, economia internacional, estudos de defesa, direitos humanos entre outros. 
de estudos e prática (Breda dos Santos, 2009).

O propósito deste artigo é rever o desenvolvimento das relações internacionais no Brasil e buscar explicar as diversas tendências que marcaram a evolução da disciplina. Ao proceder cronologicamente, $\mathrm{o}$ artigo procura tratar em grandes linhas de como nasce e evolui a área de relações internacionais, com especial atenção para os momentos formativos da disciplina. $\mathrm{Na}$ última parte, serão também feitas considerações a respeito das perspectivas para o futuro da área de RI.

\section{O PENSAMENTO SOBRE RELAÇÕES INTERNACIONAIS: AS ORIGENS NA BUROCRACIA ESTATAL E NA INTELECTUALIDADE}

O Brasil faz fronteira com nove países sulamericanos e com o departamento ultramarino francês da Guiana. A própria natureza dessa inserção geográfica do país traz uma necessidade, quase uma obrigação, de pensar o internacional. Após a independência política de Portugal, em 1822, o tema das relações internacionais brasileiras não surgiu como matéria isolada, nem tampouco foi objeto exclusivo - ou preferencial—da academia. Políticos, militares, diplomatas tomaram à frente na tarefa de avaliar e planejar como o país deveria relacionar-se com seus vizinhos e com as grandes potências, em particular o Reino Unido e, posteriormente, os EUA (Almeida, 1998; Pinheiro e Vedoveli, 2012).

Como ocorreu com a maioria das disciplinas incorporadas à academia desde o século XIX, o que depois seria visto como RI esteve diretamente ligado à formação e consolidação da identidade dos Estados nacionais (Breda dos Santos, 2005). No caso do Brasil, como bem notam Vigevani, Thomaz e Leite (2016), áreas mais tradicionais do conhecimento (história, geografia, direito, economia etc.) contribuíam de modo recorrente -ainda que assistemático- para o entendimento das relações entre o Brasil e o resto do mundo. O passado colonial de interação com as regiões vizinhas das Américas, com o circuito atlântico, com a África e, mesmo, com o império português global foi esquecido como tema nas reflexões que se iniciaram como Brasil independente. As preocupações agora eram outras, já que se tratava de uma fase em que a premência das ações de política externa modelava o pensamento: a questão central era construir uma visão do Brasil como ator internacional, com individualidade própria e propósitos que garantissem autonomia diplomática. Os "intelectuais como diplomatas" muito contribuíram para essa concepção das relações internacionais do país -portadores que eram da função de representá- lo no exterior como ente dotado de vontade unívoca (Almeida, 
1998; Fonseca Jr, 2011; Ricupero, 2016; Pinheiro e Vedovelli, 2012; Ricupero, 2011).

Os primeiros anos após a independência foram marcados pelas negociações para o reconhecimento do Brasil, pelas tratativas de definição de fronteiras, pelas disputas na bacia do Prata e pela definição das relações com o Reino Unido ${ }^{3}$. Esses temas são essencialmente examinados e analisados por diplomatas e políticos como Duarte da Ponte Ribeiro, Honório Hermeto Carneiro Leão (Marquês de Paraná), Paulino José Soares de Sousa (Visconde do Uruguai) e José da Silva Paranhos (Visconde do Rio Branco), prolíficos em textos oficiais e intervenções parlamentares voltadas para justificar as posições brasileiras. Ao longo do período imperial, um intelectual com atuação diplomática como Francisco Adolfo de Varnhagen produziu obras de relevo sobre história do Brasil, que tentavam legitimar o país como ator

3 Pode-se, mesmo, extrapolar o raciocínio sobre a organicidade do conhecimento produzido sobre relações exteriores do Brasil e tratar dos pareceres da seção de política externa do Conselho de Estado, durante o império (Feldman, 2009). Naturalmente, essa linha de argumentação traz dificuldades para verificar a autoria dos textos e necessitaria de uma análise do processo burocrático para viabilizar a compreensão do conhecimento produzido. As atas pertinentes foram publicadas na coleção Conselho de Estado e a Politica Externa do Império: Consultas da Seção de Negócios Estrangeiros, disponível em http://funag.gov.br/biblioteca/index.php?route $=$ product $/$ search $\&$ search $=0 \% 20$ conselho $\% 20$ de $\% 20$ estado, acesso em 19/9/2019. no cenário internacional (Cervo,1992; Ricupero, 2016; Pimentel, $2013^{4}$ ).

Com o advento da República, ocorre uma mudança gradual de temática, que não resulta só do novo regime, mas também da posição do Brasil no cenário regional e internacional. $\mathrm{O}$ mais notável dos diplomatas/intelectuais/políticos é ainda o Barão do Rio Branco, que teve longa carreira como diplomata, cônsul, advogado em questões arbitrais e foi Ministro das Relações Exteriores de 1902 até sua morte em 1912. O cerne de sua longa obra está nos memoriais que apresentou para defender o Brasil nas arbitragens sobre fronteiras, nos quais demonstrava conhecimento enciclopédico sobre as relações com vizinhos. São notáveis também alguns textos sobre questões históricas, especialmente as do Prata, e, como Ministro, sobre as relações com os EUA e a Europa, oferecendo esboço do que seria um paradigma que influenciaria, por bom tempo, a orientação da política externa brasileira,com base em uma "aliança não escrita" com os EUA. As primeiras décadas do século xx trouxeram também outros temas e reforçaram antigos. Ao escrever uma história da política externa (em estilo

4 A coleção coordenada por Pimentel (2013, 3 vols.) traz ensaios sobre o pensamento e a prática de diversos diplomatas, políticos e intelectuais do período de 1750 a 1964 , muitos dos quais citados aqui. Não se fará referência individual aos textos no entendimento de que o caráter coletivo da obra corrobora o ponto aqui defendido da interrelação entre operadores e pensadores das relações internacionais no Brasil. 
que ia além da história diplomática), Pandiá Calógeras (1989 [1927-1933]) reforçava as noções de nacionalidade e de individualidade do país como entidade política. As relações com os EUA tornaram-se também matéria candente. Logo no início do século $\mathrm{xx}$, na interseção entre a prática e a produção do conhecimento, reside a controvérsia entre Oliveira Lima e Joaquim Nabuco, que levaram a cabo um profícuo debate em que o primeiro manifestava recalcitrância em relação aos EUA, enquanto o segundo advogava uma aproximação com aquele país, sob a proteção do qual poderia o Brasil crescer. A incerteza sobre o posicionamento brasileiro em relação aos EUA perdurou até o fim do período entre-guerras, envolvendo vários outros intelectuais e diplomatas (Moura, 1980). Ainda característica desse período é a entrada do multilateralismo e das organizações internacionais na agenda diplomática do Brasil. Com Ruy Barbosa articulou-se o fundamento jurídico para a argumentação em favor da igualdade soberana dos Estados, conceito que será adotado como básico na construção das organizações multilaterais no âmbito regional e universal. ${ }^{5} \mathrm{Na}$ fase seguinte, da Liga das

5 A expressão do conceito por Ruy Barbosa decorre, também, de demandas políticas circunstanciais, no âmbito da II Conferência da Paz da Haia, em 1907. Não se sugere aqui que o jurista baiano tenha inventado o conceito ou sido seu mais importante articulador, mas antes que foi um dos defensores de uma tendência presente no pensamento latino-americano e que
Nações, há um momento controverso e que abre o debate sobre permanecer ou não na organização depois que, em função dos acordos de Locarno, estava bloqueada a pretensão brasileira a um assento permanente no Conselho. A solução da saída da Liga representou uma experiência traumatizante para o Brasil (Ricupero, 2016; Pimentel, 2013; Mello e Silva, 1998).

O segundo pós-guerra foi dominado, por sua vez, por duas questões inter-relacionadas, que mobilizavam a sociedade brasileira muito além da tradicional elite de relações internacionais: o posicionamento do Brasil na Guerra Fria; e o uso da política externa como instrumento de promoção do desenvolvimento econômico. A paulatina institucionalização da vida acadêmica no Brasil retiraria parte da iniciativa de políticos e diplomatas na construção do conhecimento sobre RI (Lima e Cheibub, 1983). Ainda assim, manteve-se forte a relação orgânica entre operadores e produtores de conhecimento. No campo econômico, vale citar o diplomata Edmundo P. Barbosa da Silva, que se tornou personagem de relevo, ao advogar uma diplomacia econômica ativa, que buscasse laços mais estritos com os vizinhos, $o$ aumento do fluxo comercial e a atração de capitais. O outro diplomata e economista importante foi Roberto Campos que se tornaria um dos mais

influenciou o entendimento subsequente da ideia de igualdade soberana (Finnemore e Jurkovich, 2014). 
notáveis articuladores do pensamento liberal no Brasil. Outra fonte importante para compreender a política externa brasileira foi o debate em torno das posições brasileiras na Conferência de Havana de 1947, que levou à criação do GATT. Ali estavam os primeiros elementos, ainda modestos, que diferenciavam as posições brasileiras daquelas dos países desenvolvidos. No campo político, os primeiros sinais da mudança do paradigma americanista e de modernização das doutrinas de política externa começam no governo Juscelino Kubitschek, em meados dos anos 1950, quando o país se tornou um proponente de ações multilaterais, de alcance regional, com a Operação Pan-americana, que reunia os latino-americanos em torno de reivindicações próprias diante dos EUA. A tendência de buscar autonomia prosseguiu e, neste sentido, pode-se mencionar a atitude de Afonso Arinos de Mello Franco que, como político, intelectual e Ministro das Relações Exteriores, defendeu o posicionamento do Brasil como país ocidental, mas não a reboque dos EUA, e se tornou, assim, uma figura-chave da Política Externa Independente (PEI). Incontornável também é a menção a San Tiago Dantas, articulador central da PEI que, como Ministro das Relações Exteriores, era capaz de diálogar com a sociedade e o Congresso, com alto grau de sofisticação, sobre os temas centrais de sua pasta e sobre os eventos que causavam comoção, como o posicionamento brasileiro em relação à Cuba (Pimentel, 2013; Franco, 2007).

$\mathrm{O}$ alcance da reflexão, apesar da abertura para o mundo com a PeI, ainda era limitado. Uma de suas características foi mais tarde diagnosticada pelo embaixador Araujo Castro ao assinalar que o Brasil havia desenvolvido uma política externa (suas relações bilaterais e multilaterais com outros atores) sem uma política internacional (uma compreensão mais ampla e de longo prazo sobre seu papel no mundo e sua estratégia) (Amado,1982: 197-198).

As mudanças políticas refletem e incorporam movimentos que ocorriam no plano do debate intelectual. No fim dos anos 1950, a academia já se encontrava suficientemente estruturada para produzir um manancial constante de conhecimento, ainda que historiadores, economistas, sociólogos, juristas dificilmente identificassem seus estudos como relações internacionais na condição de área específica (Lima e Cheibub, 1983: 53-56). No campo da história, é interessante anotar a combinação de perspectivas tradicionais e outras, mais críticas e modernas. Até aquele momento, a maioria dos pioneiros do estudo das relações internacionais, em especial no campo da história diplomática do Brasil, seguiam de perto o discurso oficial.Em autores como Delgado de Carvalho, prevalecia a tentativa de construir uma história nacional de cariz positivista, no estilo rankeano (Breda dos Santos, 2005). 
Começavam a surgir, porém, com outras perpectivas metodológicas, obras abertamente críticas sobre o conjunto da política externa, como as de José Honório Rodrigues, que se descolavam do discurso estatal, mas se mantinham no campo da construção do conhecimento sobre o poder nacional. ${ }^{6}$ De modo justificável ou não, os agentes do Estado eram entendidos como os atores principais - senão únicos (Almeida, 1998: 65-93; Casarões, 2018).

Até aquele momento, o estudo das relações internacionais no Brasil era marcado, em grande parte, pela importância do conhecimento voltado para intervir na realidade. Era clara a ausência de bases teóricas explícitas. Isso mudou paulatinamente, e uma das expressões das nova tendência foram os estudos militares (muitas vezes realizados por militares como Golbery do Couto e Silva ou Carlos de Meira Mattos - embora houvesse civis notáveis, como Therezinha de Castro), que se valeram dos fundamentos lançados pelos vários teóricos da geopolítica. Os cursos da Escola Superior de Guerra (ESG) eram iniciados por uma introdução a uma teoria sobre as bases e os fatores do poder, com características próximas ao realismo clássico. Sobretudo no período do regime militar,

6 Embora muitos historiadores, sociólogos e economistas tenham pensado o Brasil e sua história a partir de graus variados de relação com o marxismo, era raro que se ativessem a temas que pudessem ser vistos como internacionais. A preocupação com a política externa do país era ainda mais incomum. essa perspectiva influenciou os cursos de formação dos diplomatas. A contribuição dos estudos de geopolítica permaneceu praticamente restrita aos círculos que lhe deram origem. $\mathrm{O}$ caráter instrumental de seu arcabouço teórico —voltado para justificar as políticas estatais - foi fator relevante para que a produção geopolítica tivesse um impacto menor sobre a disciplina de relações internacionais no Brasil (Lima e Cheibub, 1983; Miyamoto, 1995).

Em um ponto quase diametralmente oposto- pela concepção centro-periferia da CEPAL, pelas bases teóricas neo-marxistas e pelo projeto de esquerda de muitos de seus proponentes - estava a teoria da dependência - ainda hoje vista como uma contribuição original latino-americana para a compreensão da realidade global. Mesmo que não seja necessariamente caraterizada como uma teoria das relações internacionais, de fato faz importantes aportes nessa área e tenta fazê-lo a partir do ponto de vista dos agentes periféricos. Seus autores brasileiros mais conhecidos, como Ruy Mauro Marini, Theotônio dos Santos, Fernando Henrique Cardoso, entre outros, partiram de percepções estruturalistas do cenário internacional, a fim de examinar as possibilidades e os limites da atuação dos países como o Brasil. Em geral, suas conclusões foram pessimistas, sempre apontando para a pouca margem de manobra e ressaltando o caráter incompleto da formação do que se chamava, então, 
de país subdesenvolvido. As soluções para avanços progressistas estavam na mudança das estruturas de poder nacional e no modelo de inserção no sistema capitalista internacional e não na diplomacia. Nas variadas versões da teoria da dependência, houve esforços de articular uma melhor compreensão de como se forma a política externa, em especial os de Carlos Estevam Martins (1975) e de Otávio Ianni (1978). Ironicamente, a teoria da dependência, que pode ser vista como a formulação mais original de autores brasileiros na teoria das relações internacionais, foi gradativamente abandonada, seguindo o destino da maioria das análises estruturalistas após o colapso do bloco soviético e o advento do neoliberalismo (Casarões, 2018; Fonseca Jr., 2011; Tickner, 2008; Pinheiro e Lima, 2018).

A inflexão no estudo das relações internacionais no Brasil em direção a um modelo acadêmico mais consistente se inicia com as contribuições de Helio Jaguaribe que, em 1954, fundou o Instituto Brasileiro de Relações Internacionais (IBRI) e, em 1958, a Revista Brasileira de Política Internacional (RBPI). Durante as primeiras décadas de seu funcionamento, a RBPI contou com forte e contínua contribuição de diplomatas, além de servir de veículo para dar publicidade às ações internacionais da diplomacia (ao estampar em suas páginas documentos, tratados, declarações etc.) (Lessa, 2014). Publicado no mesmo ano da fundação da revista, o livro "O nacionalismo na atualidade brasileira", de Jaguaribe, foi um marco no desenvolvimento do campo das relações internacionais. $\mathrm{O}$ texto não se propõe a estabelecer uma fronteira estanque entre interno e internacional; ao contrário, explicita as bases domésticas da postura internacional de diversos grupos no Brasil e suas consequências para o desenvolvimento do país. O autor refletia uma época de grande ebulição intelectual em que, assim como os militares da geopolítica, civis no IBRI e em outras entidades, como o Instituto Superior de Estudos Brasileiros (ISEB, fundado em 1955), pensavam a realidade do Brasil e sua inserção no mundo Em certo sentido, dialogavam com a teoria da dependência, mas em um enfoque menos estrutural. É o momento de proposição de modelos modernos para a construção nacional, como o desenvolvimentismo de Juscelino Kubistchek, que se exprimeriam pela PEI na política externa. Esse caminho para a modernização foi interrompido com a tomada do poder pelos militares em 1964. A reflexão sobre diplomacia ganhou, então, perspectiva crítica à política externa do governo militar, como na revista Política Externa Independente (1965-1966), ${ }^{7}$ que, embora volta-

7 No caso da revista Política Externa Independente, o diálogo com a teoria da dependência era mais implícito do que explicito. Há autores da dependência que escreveram para o periódico, como Andre Gunder Frank, mas a revista (que teve apenas três números) estava voltada, sobretudo, à formulação de uma crítica contundente à política externa do governo Castello Branco, 
da para a análise de questões conjunturais como a invasão da República Dominicana e a reforma da oEA, trazia artigos mais ambiciosos que lidavam com a inserção do Brasil no mundo e temas gerais do sistema internacional (Jaguaribe, 2013; Lima e Cheibub, 1982: 84-85; Fonseca Jr, 2011; Tickner, 2008).

No período militar, o pensamento não permaneceu estático, especialmente em razão das fraturas no paradigma americanista. A aliança com os EUA não está isenta de conflitos e contradições. Começam a se definir, não exclusivamente a partir da esquerda, opções conceituais para colocar o Brasil como um ator autônomo no sistema internacional e, portanto, resistente à visão de mundo que os EUA defendiam. O melhor exemplo é o de Araujo Castro, diplomata e intelectual, que confirma a polinização cruzada entre diplomacia e academia brasileiras. Araujo Castro desenvolveu, também ao longo dos anos 1950, 1960 e 1970, conceitos que muito se aproximavam do acadêmico. Seu raciocínio tentava superar o engessamento Leste-Oeste ao propor uma perspectiva brasileira para Norte-Sul. Procurava na estrutura do sistema internacional (em especial nas organizações internacionais) as frestas pelas quais um país como o Brasil poderia agir com autonomia relativa e mitigar o

com artigos de autores como Antonio Houaiss (diplomata cassado em 1964) e José Honório Rodrigues. poder das superpotências. Para tanto, articulou propostas que combinaram, no plano multilateral, as lutas do Terceiro Mundo em torno dos objetivos de desarmamento, desenvolvimento e descolonização. Eram os elementos da "política internacional" que Castro falava como caminho para superar os limites de uma "política externa”. Merecem destaque as referências explícitas que fazia a trabalhos acadêmicos, como os de Morgenthau, ${ }^{8}$ cuja teoria procurava reinterpretar. Não só Araujo Castro agia assim, o Ministério das Relações Exteriores procurava ciosamente manter-se informado das teorias e análises em voga, assinava periódicos e recebia dos postos no exterior bibliografia atualizada (sobretudo a respeito de direito internacional e organismos internacionais), que podia ser consultada pelos diplomatas - em uma época em que poucas instituições no Brasil podiam ter acesso a recursos semelhantes (Amado, 1982: 139-164; Vargas, 2013; Mello e Silva, 1998; Lima e Milani, 2016).

8 Vargas (2013: 47-48) acredita que o conhecimento da produção acadêmica sobre relações internacionais não era típico dos diplomatas, tratando-se de idiossincrasia de Araujo Castro. Há pouca evidência direta de referências a autores acadêmicos por diplomatas nesse período, mas a aquisição sistemática de obras sobre relações internacionais pelos postos no exterior e a produção de diplomatas que posteriormente atuariam como professores da UnB, entre outros fatores, sugere que ao menos parte dos funcionários diplomáticos do Ministério procurava manter-se atualizada e dialogar intelectualmente com a academia. 
Nos anos 1960, Celso Lafer daria outra contribuição fundamental ao introduzir, de modo explícito, elementos da ciência política dos EUA na análise das relações internacionais do Brasil. Em seus primeiros ensaios, Lafer (1967, por exemplo) usou conceitos eastonianos de sistema para relacionar os níveis global, regional e nacional, tratando da política externa brasileira desde o Império até meados da década de 1960. $\mathrm{O}$ autor continuou a publicar sobre vários aspectos de relações internacionais e, tendo assumido a função de Ministro das Relações Exteriores duas vezes (1992 e 2001-2002), procurou usar a prática diplomática para incrementar o pensamento acadêmico. Lafer também foi pioneiro ao introduzir no Brasil o pensamento de Raymond Aron, Norberto Bobbio e da escola inglesa. O destaque alcançado pelo Brasil no cenário internacional também encorajou acadêmicos estadunidenses como Roger Fontaine, Ronald Schneider, Riordan Roett, Michael Morris, Frank McCann Jr, Stanley Hilton, entre outros, a tomar a posição brasileira no mundo como seu objeto de análise, por meio de teorias e métodos típicos das ciências sociais dos EUA. Esse desenvolvimento encorajou a lenta autonomização das relações internacionais como objeto e disciplina, o que seria consolidado a partir de meados da década de 1970 nas instituições acadêmicas brasileiras. Ainda persistiu, durante bastante tempo, um caráter normativo e prescritivo nas análises brasileiras das relações internacionais, apesar de essa característica militar contra o projeto de buscar uma disciplina orientada por critérios acadêmicos e objetivos (Fonseca Jr., 1989; Fonseca Jr., 2011; Fonseca Jr., 2018; Lima e Cheibub, 1983).

\section{As RELAÇÕES INTERNACIONAIS COMO DISCIPLINA E A FORMAÇÃO DAS INSTITUIÇÕES ACADÊMICAS}

O estabelecimento da graduação em relações internacionais na Universidade de Brasília (UnB) foi um marco do estudo da disciplina no Brasil. Criado em 1974, o curso da UnB foi durante vários anos o único no Brasil a organizar o ensino e a pesquisa de RI de um modo acadêmico. Sua estruturação foi feita em estreita cooperação entre a universidade e o Ministério das Relações Exteriores, que via no curso uma oportunidade de formação de especialistas no tema, ainda que a preparação dos diplomatas fosse mantida à parte, no Instituto Rio Branco. Diplomatas opinaram sobre a estrutura da nova graduação e integraram o quadro de professores (Julião, 2012; Azevedo, 2018).

A origem da fase acadêmica das relações internacionais no Brasil contrasta, desse modo, com o estabelecimento da cátedra Woodrow Wilson em Aberystwyth. $\mathrm{Na}$ escola pioneira em 
Gales, uma doação privada, motivada pela hecatombe da Primeira Guerra Mundial, resultava em uma instituição voltada para entender o conjunto do cenário internacional. No caso brasileiro, uma colaboração próxima do Executivo com uma universidade federal atendia às necessidades de um país que expandia seus horizontes e demandava agentes capazes de operar no campo internacional (Azevedo, 2018; Julião, 2012; Fonseca Jr, 2011; Breda dos Santos, 2005). Em um certo sentido, é possível afirmar que o estudo das relações internacionais ganhava sua autonomia como disciplina acadêmica sem negar suas raízes no campo mais amplo das relações internacionais como prática e área de atuação, inclusive do Estado. No dizer de Vigevani, Thomaz e Leite (2016: 3): “...o Estado constitui referência concreta e simbólica” da institucionalização das RI.

Uma conjunção de fatores contribuiu para o início dessa nova fase. Estavam relacionados, por um lado, à dinâmica intelectual e institucional da disciplina e, por outro, à evolução do cenário internacional e como o Brasil nele se inseria. No que tange a esse segundo aspecto, as crises econômicas por que passava a ordem global, com o fim da conversibilidade do dólar (1971) e o primeiro choque do petróleo (1973), foram de grande relevância para estimular novos questionamentos. Na vertente política, a détente entre EUA e URSS — no que era percebido à época como o fim da Guerra Fria- e o crescente ativismo do bloco terceiro-mundista encorajaram um renovado interesse pelo cenário internacional percebido como revolucionário. Exemplo das novas percepções foi o conceito de "congelamento do poder mundial”, enunciado por Araujo Castro no início da década de 1970 (Amado, 1982: 197-212). O Brasil, que ganhava espaço no sistema internacional com o "milagre" econômico, operou mudanças dramáticas em sua política externa com o pragmatismo responsável e ecumênico do presidente Ernesto Geisel e do chanceler Azeredo da Silveira (1974-1979). Houve uma aproximação com o Terceiro Mundo e uma afirmação de autonomia em relação aos EUA, que se materializavam em temas como aproximação com a África (foi o primeiro país a reconhecer o governo do mpla em Angola) e o mundo árabe (mudança de votos sobre o Oriente Médio, especialmente sobre a resolução que equiparou sionismo e racismo, em 1975) e a denúncia do acordo de cooperação militar Brasil-EUA, em 1977. Ao mesmo tempo, ampliavam-se os movimentos de distensão e aproximação com a entorno regional, que se concretizaram com o acordo com a Argentina sobre a construção da hidrelétrica de Itaipu, em 1979. Tornou-se evidente, naquele momento, que, mesmo estruturalmente balizado por sua condição periférica e "subdesenvolvida", o país operava de modo criativo e inesperado nos meios diplomáticos. A redemocratização, alcançada na segunda metade dos anos 1980, ampliou o espectro de interesses 
do país que se viu menos constrangido por temas de direitos humanos e meio ambiente. Era crescentemente necessário explorar análises e encontrar explicações para esses fenômenos (Lima e Cheibub,1983; Fonseca Jr, 2011; Ricupero, 2016; Pinheiro e Lima, 2018).

No que diz respeito à dinâmica intelectual e institucional da disciplina, houve inovações consideráveis na academia. A evolução política e econômica dos "Trinta Gloriosos" abriu espaço para novas interpretações das organizações internacionais inspiradas pelo liberalismo, trazendo ao proscênio a ideia de interdependência. A reação teórica que acabaria por prever a retomada dos atritos entre as superpotências não tardaria, na forma do neo-realismo e sua obsessão por modelos parcimoniosos. Também o campo da análise de política externa se desenvolvia rapidamente após os estudos pioneiros da década de 1960 (Ponte e Messari, 2005; Faria, 2012; Salomon e Pinheiro, 2013). As teorias consideradas pelos analistas brasileiros -imperialismo e suas variantes, dependência, geopolítica e realismo- tinham dificuldade em lidar com a complexidade do real, a prática da política externa e as mudanças no cenário internacional. A academia, sempre em interação com os operadores, percebia essas lacunas (Fonseca Jr, 2011).

As novas tendências teóricas foram gradualmente fincando raízes no Brasil, e uma geração de acadêmicos contribuiu para consolidar as relações internacionais como um campo intelectual à parte e capaz de ampliar e aprofundar as análises existentes. Em sua maioria, eram egressos da história ou da ciência política e defenderam teses ao longo dos anos 1970 ou no início dos 1980, em geral em universidades estrangeiras, pela ausência de oportunidades de pós-graduação no Brasil - Gerson Moura, Maria Regina Soares de Lima, Monica Hirst, Tullo Vigevani, Amado L. Cervo, Alexandre S.C. Barros, Shiguenoli Miyamoto, entre outros ${ }^{9}$. O livro de Moura (1980) traz um bom exemplo. O autor propõe-se a buscar uma superação do que vê como dificuldades teóricas dos behavioristas e dos estruturalistas, isto é, tenciona dar conta de como, dentro das limitações existentes no cenário internacional, a diplomacia brasileira buscara otimizar a posição do país na conturbada década de 1930 . O conceito resultante, "autonomia na dependência”, partia do vocabulário existente no discurso oficial e em versões sistematizadas da percepção diplomática, tais como a de Araujo Castro, bem como de ideias desenvolvidas por Jaguaribe

9 A ida de jovens acadêmicos em busca de pós-graduação no exterior evidenciava a carência brasileira de uma estrutura de ensino superior capaz de qualificar os estudantes acima de um certo nível, que se refletia em grande parte na extrema escassez de doutores. No momento de crescimento acelerado do Brasil, nos anos 1970, com o país sendo objeto de interesse internacional, vários pesquisadores puderam estudar no exterior com bolsas oferecidas por entidades estrangeiras como a Fundação Fullbright e a USAID (Lima e Cheibub, 1983; Herz, 2002; Lessa, 2005; Fonseca, Jr, 2011). 
e pelos teóricos da dependência para renovar a análise acadêmica. $\mathrm{O}$ conceito e suas ramificações tornaram-se, nas décadas subsequentes, essenciais nos debates sobre política externa brasileira e sua história. Foram reapropriados pelo discurso oficial para sinalizar as modalidades de estratégia para a atuação internacional do Brasil, que, justamente no fim dos anos 1970, tinha acentuado a trajetória de autonomização de sua política externa $(\mathrm{Ca}$ sarões, 2018: 410; Herz, 2002; Fonseca Jr, 2011; Lima e Milani, 2016; Pinheiro e Lima, 2018).

A graduação em RI da UnB permaneceu, porém, por mais de uma década, como a única no Brasil; e a segunda a ser criada, na Universidade Estácio de Sá, tinha como ênfase a operação em comércio internacional. Um movimento importante o ocorre já em 1980, quando pesquisadores constituem um grupo significativo, em termos de número e da qualidade da produção, e assim começam a se organizar de forma sistemática. Foi instituído o Conselho Brasileiro de Relações Internacionais (CBRI) e um grupo de trabalho (GRIPE) no âmbito da associação de cientistas políticos (ANPOCS) (Barros, 1985: 52; Julião 2012; Lima e Milani,2012; Vigevani, Thomaz e Leite, 2016). A maioria dos pioneiros em RI tinha que realizar suas pesquisas nessa área como parte subsidiária das atividades em outros campos do conhecimento. Nos órgãos de fomento à pesquisa, a disciplina de relações internacionais foi reconhecida ainda na década de 1980, mas não obteve um grau adequado de autonomia. (Azevedo, 2018; Miyamoto, 2003; Miyamoto, 1999). Nessa configuração, as relações internacionais eram percebidas como um sub-campo da ciência política, e acabavam por receber alocação inadequada de recursos financeiros. As primeiras pós-graduações - essenciais para fazer avançar a disciplina- foram estabelecidas na UnB, em 1984, e na Pontifícia Universidade Católica do Rio de Janeiro (PUC-Rio), em 1987. Mas a maioria das dissertações e teses continuaram (e continuam) a ser defendidas em programas que não são especificamente de RI (Faria, 2012: 114-115; Breda dos Santos e Fonseca, 2009; Vigevani, Thomaz e Leite, 2016).

Assim como no caso da criação do curso de relações internacionais na UnB, houve uma mediada de participação do Ministério das Relações Exteriores na expansão das pesquisas acadêmicas da disciplina no Brasil. Diplomatas individualmente continuaram a produzir livros e artigos sobre a política externa brasileira e sua história e sobre aspectos variados de relações internacionais. A partir de 1979, o MRE passou a exigir, como requisito para ascensão funcional, a produção de um trabalho para o Curso de Altos Estudo (CAE), ${ }^{10}$ o qual não retém

10 http://www.institutoriobranco.itamaraty. gov.br/curso-de-altos-estudos, acesso em 5/9/2019. 
todas as características de uma tese acadêmica (sobretudo por não privilegiar questões teóricas e metodológicas) mas permite um levantamento sistemático do pensamento dos diplomatas brasileiros. A começar no fim da década de 1980, muitos trabalhos do CAE foram publicados e têm sido utilizados, seja como bibliografia, seja como fonte para compreensão das políticas oficiais. A partir de meados daquela década, o Ministério também vinha estimulando o desenvolvimento do estudo das RI no Brasil por meio da Fundação Alexandre de Gusmão (FUNAG) e do Instituto de Pesquisas em Relações Internacionais (IPRI). ${ }^{11}$ Essas entidades engajaram-se cedo com a nascente comunidade acadêmica, encomendando estudos e promovendo eventos. A reação a essas atividades do Ministério não foi unânime. Especialmente nos primeiros anos, pelo ineditismo da iniciativa, uma parte da comunidade acadêmica questionou o que via como possibilidade de controle do Estado sobre recursos para pesquisa ou como intrusão do discurso oficial na produção do conhecimento; outros entendiam como essencial o encorajamento aos estudos de RI e um intercâmbio entre a prática diplomática e a análise acadêmcia (Barros,

11 Embora a FUNAG tenha sido formalmente criada em 1971, começou a funcionar efetivamente só no fim daquela década. O IPRI foi estabelecido em 1987. Ver http://www. funag.gov.br/index.php/pt-br/funag, acesso em 6/9/2019.
1985; Fonseca Jr, 2011; Fonseca Jr, 1989; Julião, 2012; Pinheiro e Vedoveli, 2012).

Nas décadas de 1980 e 1990, o crescimento do campo das relações internacionais no Brasil deveu-se também ao lento processo de redemocratização do país, cujo início é normalmente datado de meados da década de 1970 (com a "abertura lenta, gradual e segura" de Geisel) e culmina com a nova Constituição, em 1988, quando se afasta definitivamente qualquer vestígio de censura no país. As RI, assim como as demais disciplinas acadêmicas, beneficiaram-se da liberdade de expressão reconquistada e se engajaram no debate de temas controversos, como segurança nacional, indústria bélica, direitos humanos, entre outros. A abertura econômica do Brasil para o mundo (em especial com o Mercosul) atraiu os interesses de novos atores para temas internacionais, tais como associações empresariais, sindicatos, entidades da sociedade civil e outros ministérios, os estados e os maiores municípios. Além de novos interesses, esses atores trouxeram consigo oportunidades de emprego para os profissionais da área e de financiamento de estudos. Como afirmam Lima e Milani (2016):

“(...) a coincidência entre os dois movimentos (liberalização política e abertura econômica) deu início a uma nova fase da política externa do país (...). Nessa etapa, assiste-se a 
uma nova realidade, uma vez que a política externa, antes caracterizada pela condução de políticas sem efeitos distributivos, passou a ter de contemplar interesses setoriais, que se refletiram na alegada histórica autonomia relativa do Itamaraty na condução da política externa. Com a renovação da agenda política da PEB também se renovou a agenda acadêmica, mais plural e numerosa graças ao avanço institucional e à profissionalização progressiva dos programas de pesquisa e pós-graduação no país”.

O processo de redemocratização e a persistência das pesquisas relativas às relações internacionais do Brasil levaram a discussões relevantes também sobre o acesso aos documentos produzidos pelo Estado como fontes para pesquisa. Tradicionalmente, a diplomacia é conhecida por sua discrição e relutância em revelar pormenores de negociações, o que se somou, no caso brasileiro, aos períodos de governo autoritário, de modo a dificultar o acesso aos arquivos. Ainda que pesquisadores estrangeiros, por comparação com outros países latino-americanos, chegassem a elogiar os procedimentos no Brasil, a impressão dos brasileiros era de um processo imprevisível e sacrificante. Com o retorno do país à democracia, $\mathrm{o}$ acesso aos arquivos tornou-se uma discussão ligada à liberdade de informação, na qual poucos, à exceção dos próprios agentes do Estado, argumentavam abertamente em favor da legitimidade e conveniência de manter o sigilo de parte da documentação. Embora o arcabouço legislativo tenha evoluído de modo significativo e culminado com a Lei de Acesso à Informação ${ }^{12}$, de 2011, em casos específicos, alguns pesquisadores continuam insatisfeitos com as limitações de acesso e a forma como se dá. Em parte como decorrência dos obstáculos existentes, formou-se uma tendência a embasar parte da pesquisa empírica, sobretudo de temas contemporâneos, em documentos públicos. É recente, porém, a atenção quanto à necessidade de criticar sistematicamente as fontes, ostensivas ou classificadas, de modo a otimizar a qualidade da pesquisa em relações internacionais no Brasil (Carneiro, 1989/1990; Costa e Fraiz, 1989; Lafer,1989/1990; Lima e Cheibub, 1983: 53; Penna Filho, 1999; Seckinger, 1975: 136-140; Vigevani, Thomaz e Leite, 2016: 8; Waisbich, Cetra e Marchezini, 2017; Uziel e Breda dos Santos, 2019).

12 Lei 12.527, de 19 de novembro de 2011. Íntegra disponível em http://www.planalto.gov. br/ccivil_03/_ato2011-2014/2011/lei/112527. htm, acesso em 6/9/2019. 


\section{A EXPANSÃO DAS RELAÇÕES INTERNACIONAIS E A IDENTIDADE DE UMA DISCIPLINA}

Para descrever o desenvolvimento do campo das relações internacionais no Brasil a partir da segunda metade da década de 1990 e, sobretudo, dos anos 2000, são com frequência usados termos como "explosão" e "crescimento exponencial". Mesmo se deixarmos de lado as hipérboles e imprecisões matemáticas, a expansão da disciplina institucionalizada e da produção do conhecimento em geral sobre RI no Brasil foi impressionante. Se, em meados da década de 1980, havia só duas graduações em RI, entre 1995 e 1999 , foram criadas 17 , entre 2000 e 2010 , 84 e entre 2011 e 2017, 43. Calculava-se, em 2012, que mais de 13 mil vagas eram oferecidas por ano nos cursos e que cerca de 10 mil pessoas se graduavam em relações internacionais todos os anos. Não há consenso, entretanto, sobre as causas desse crescimento acelerado ou sobre a possibilidade de que seja um fenômeno singular da área de relações internacionais. $\mathrm{O}$ crescimento inicial foi marcado pelo grande número de instituições privadas, que optaram por abrir, pelo baixo custo, cursos de RI, seguidas eventualmente das grandes universidades públicas, nas quais ainda se localiza a maioria das pós-graduações (Azevedo, 2018: 139; Julião, 2012; Pfrimer e Okado, 2019). Os autores, com frequência, apostam em uma multicausalidade para explicar o maior interesse por relações internacionais. Por um lado, são alinhadas causas atinentes ao campo intelectual, como o fim da repressão política, o desejo de explicar a inserção internacional mais saliente do Brasil e, mesmo, a "glamourização" da disciplina (Vigevani, Thomaz e Leite, 2016; Pecequilo, 2017). Por outro, fala-se de estímulo material, como o aumento do número de vagas em entidades públicas e privadas e as oportunidades de empreendedorismo surgidas da abertura comercial. Não há, até o momento, consenso sobre quais fatores são os mais relevantes (Herz, 2002; Pfrimer e Okado, 2019; Myiamoto 2003).

É certo que o número de cursos de RI e, posteriormente, de pós-graduações acompanhou e superou o crescimento dos cursos superiores no Brasil. De particular relevância foi o investimento estatal no campo das relações internacionais: os editais San Tiago Dantas, de 2000, e Renato Archer, de 2006, viabilizaram o estabelecimento de novos cursos e centros de pesquisa por meio do oferecimento de bolsas e recursos para compra de equipamentos e pagamento de funcionários (Breda dos Santos e Fonseca, 2009; Vigevani, Thomaz e Leite, 2016). Na década de 1990, o aumento do interesse permitiu que fossem estabelecidos foros, muito mais amplos do que os embrionários de quinze anos antes, na forma de grandes encontros nacionais de estudantes, professores e pesquisadores (eNERI e FENERI). A fundação 
da Associação Brasileira de Relações Internacionais (ABRI), em 2005, contribuiu tanto para tornar mais autônoma a disciplina quanto para dinamizar seus estudos (Saraiva, 2012; Faria, 2012; Almeida, 2016). A difusão de meios eletrônicos de publicação tornou possível um incremento substancial das publicações. Antes, eram poucas e descontínuas, mas cresceram rapidamente em número, alcançando 22 em 2014, sem contar periódicos multidisciplinares que também trazem artigos de RI. Para superar as dificuldades impostas pelo idioma, muitas passaram a publicar parcial ou integralmente em inglês (Lessa, 2005; Lessa, 2014). Parte integral da expansão das relações internacionais no Brasil foi o crescente papel da Fundação Alexandre de Gusmão (FuNAG), ligada ao Ministério das Relações Exteriores, como promotora de eventos e editora de grande espectro de obras (Gusmão, 2012; Gusmão, 2016).

De fato, a evolução política e as mudanças sociais no Brasil alteraram as relações entre o Ministério das Relações Exteriores e os demais atores envolvidos nas relações internacionais, em particular a academia. No que concerne à formulação da política externa brasileira, não há dúvida da multiplicação de partes interessadas. Vigevani, Thomaz e Leite (2016) corroboram a percepção de que houve um declínio do "insulamento burocrático" do Ministério, que teve por contrapartida uma polarização em torno das posições de política externa. Lima e Milani (2016) seguem a mesma perspectiva e afirmam que “...o Itamaraty não é mais (...) uma ilha de conhecimento, tradição e experiência isolada do restante da política democrática brasileira”. Faria (2012) sugere que o aumento do número de cursos de RI contribuiu para "quebrar o monopólio do Itamaraty”. Quanto às contribuições acadêmicas feitas por diplomatas individualmente ou pelo Ministério como instituição, houve uma diluição em um ambiente acadêmico crescente, mas foi mantida sua relevância. A título de exemplo, as teses defendidas por diplomatas como requisito funcional ainda representavam, em 2016, $20 \%$ das produzidas no país (Gusmão, 2016). Existe uma percepção de que esse ativismo decorre de uma estratégia para legitimar a política externa e cooptar a classe acadêmica, a qual seria potencializada pela "curiosa ausência de uma visão crítica da política externa brasileira na academia" (Farias, 2011: 17). As reações acadêmicas variam em um amplo espectro que parte dos que reconhecem a contribuição relevante da "academicização" dos estudos diplomáticos como produtora de análises e conceitos úteis (Breda dos Santos e Fonseca, 2009; Vigevani, Thomaz e Leite, 2016; Gusmão, 2016) até os que advogam sejam os diplomatas tratados apenas como fontes primárias e desqualificam mesmo sua produção individual, ainda que oriunda de ambiente acadêmico (Saraiva, 2012; Pinheiro e Vedoveli, 2012).

Apesar de sua separação de outras áreas ser relativamente recente, $\mathrm{o}$ 
campo das relações internacionais é notável na produção de textos sobre sua trajetória. Essa busca das origens parece refletir uma busca de identidade. Os autores são claros quanto ao inescapável ecumenismo das RI no Brasil (Lessa, 2005). Como explicitou Cervo (1992: 393) “... nenhum ramo das ciências sociais depende tanto do intercâmbio científico (...) como as relações internacionais". Essa procura do que é específico das relações internacionais tem sido valorada tanto de modo positivo, quanto negativo (Myiamoto, 2003). Depois das prematuras tentativas de definir o praticante de RI como profissional à parte, ainda na década de 1970 (Julião, 2012), ficou claro que um dos grandes trunfos desse campo é sua versatilidade, a possibilidade de ocupar a função tradicional de diplomata, mas também de trabalhar em outras entidades públicas e privadas, como uma ampla gama de temas. No que concerne à utilização da teoria, por exemplo, a maior parte da produção acadêmica e grande parte das análises práticas evitam compromissos teóricos rígidos ou são ecléticas. O cenário é marcado por soluções variadas, em que nem sempre o quadro teórico se reflete na pesquisa substantiva. (Lake, 2011; Barasuol e Silva, 2016).

É na área acadêmico-institucional que se encontram os maiores dilemas. O primeiro é a dificuldade de identificar os limites entre o "fazer" e o "estudar" (Pecequilo, 2017: 3), que está presente também na relação complexa entre diplomacia e academia discutida acima. Existem pressões por cursos mais práticos, que melhor qualifiquem profissionais para o mercado de trabalho, mas que não necessariamente se adequariam aos requisitos de ensino e pesquisa. Esse primeiro quesito se manifesta igualmente na disputa por espaço na imprensa, que cada vez mais demanda comentaristas de relações internacionais, frequentemente oriundos do mundo acadêmico, mas nem sempre da área específica de RI. O segundo diz respeito à própria estrutura dos cursos de relações internacionais, que padecem de várias dificuldades -tais como professores não especializados, bibliotecas limitadas, falta de proficiência em idiomas-que prejudicam particularmente a área. Mas há quem reclame de uma atenção excessiva a métodos e temas importados e à preferência por questões chamativas em detrimento das relevantes ${ }^{13}$ (Saraiva, 2012; Myiamoto, 2003; Faria, 2012; Gusmão, 2012; Gusmão, 2016; Farias, 2011).

As observações anteriores são um sinal da capacidade que o campo desenvolveu de refletir sobre o seu próprio desenvolvimento, sobre os impasses que encontra e sobre a exigência de autocrítica. Além dos problemas internos da disciplina, haveria outros

13 A qualificação do que é relevante ou chamativo é naturalmente subjetiva, mas parte essencial da definição dos limites do campo e da contribuição acadêmica para a compreensão da política externa, segundo a opinião de acadêmicos experimentados na disciplina. 
que derivam das dificuldades que enfrenta a formação superior diante das restrições financeiras, da recessão que diminui a oferta de empregos, que se combinam para caracterizar a crise do ensino e da pesquisa no Brasil. Depois de anos de expansão, a oferta de cursos de RI começa a se contrair, acentuando a tendência a se concentrar no Sudeste (Pfrimer e Okado, 2019).

A despeito das dificuldades, o balanço da contribuição acadêmica para a reflexão sobre o papel do Brasil no mundo é significativo. A percepção sobre a identidade internacional do país foi objeto de longo debate e as referências sobre o que significa são mais claras hoje. As opções de política externa perderam a rigidez, com produção importante sobre as posições multilaterais do Brasil, especialmente nas Nações Unidas, sobre o papel do país na América do Sul (e especialmente o Mercosul), na África, no Oriente Médio, e na Ásia. O BRICS deu origem a uma vasta literatura. Os temas novos, como direitos humanos e meio ambiente, animaram debates e produção intelectual respeitada internacionalmente. Os estudos sobre segurança se tornaram mais sofisticados com um intercâmbio sistemático entre as e as instituições civis. Talvez ainda faltem debates mais abrangentes sobre teoria, reflexões mais sistemáticas sobre as transformações globais na ordem sistema (Lessa, 2014; Saraiva, 2012). É preciso reconhecer que os desafios novos são especialmente complexos e começam pela própria dificuldade de caracterizar o sistema de poder e os limites entre a vida internacional e a doméstica, diante da ampliação da agenda internacional e da emergência dos novos atores (Adelman, 2017). Mas, com o acervo construído no Brasil, o debate sobre a complexidade do presente pode apoiar-se na oferta acadêmica de racionalidade e objetividade. Não é possível, porém, garantir que essas virtudes prevaleçam. Os interesses, especialmente em tempos polarizados, tendem a esquecê-las.

\section{REFERÊNCIAS}

Adelman, J. (2017). "What is global history now?”, in Aeon, disponível em https:// aeon.co/essays/is-global-history-still-possible-or-has-it-had-its-moment, acesso em 18/9/2019.

AlmeidA, P.R. (1998). Relações internacionais e política externa do Brasil (Porto Alegre: Editora da Universidade).
. (2016) O estudo das relações internacionais no Brasil, disponível em https://diplomatizzando.blogspot. com/2016/04/o-estudo-das-relacoes-internacionais-do.html, aceso em 19 de agosto de 2019.

Amado, R. (1982). Araújo Castro (Brasília: $\mathrm{UnB}$ ). 
Gelson Fonseca Junior \& Eduardo Uziel

Notas sobre o campo das relações internacionais no Brasil no centésimo aniversário da disciplina

Azevedo, Denizar A. (2018). Raymond Aron $e$ os Estudos em Relações Internacionais na $U n B$, dissertação de mestrado (Brasília: UnB).

Barasuol, F. e Silva, André R. (2016). "International Relations Theory in Brazil: trends and challenges in teaching and research", in Revista Brasileira de Política Internacional, vol. 59 (2).

Barros, Alexandre de S. C. (1985) 'El estúdio de las relaciones internacionales em Brasil”, in Perina, Rubén, El Estudio de las Relaciones Internacionales em America Latina y el Caribe (Buenos Aires: Grupo Editor Latinoamericano).

Breda dos Santos, N. (2005). "História das Relações Internacionais no Brasil: esboço de uma avaliação sobre a área", in História, vol. 21 (1).

Breda dos Santos, N. e Fonseca, Fúlvio E. (2009). “A Pós-Graduação em Relações Internacionais no Brasil”, in Contexto Internacional, vol. 31 (2).

Calógeras, Pandiá (1989 [1927-1933]). A Política Exterior do Império, Biblioteca Pedagógica Brasileira, em 3 volumes, reeditados, em edição fac-similar (Brasília: Senado Federal).

Carneiro, Maria Luiza Tucci (1989/1990). "O guardião da memória diplomática", in Acervo, vol 4 (2)/5 (1).

Casarões, G. (2018). "The Evolution of Foreign Policy Studies”, in Ames, Barry Routledge Handbook of Brazilian Politics (Nova York: Routledge).

Cervo, A. (1992). "A Historiografia Brasileira das Relações Internacionais”, in Revista Interamericana de Bibliografia, vol. XLII (3).
Costa, Célia M. L. e Fraiz, Priscila M. V. (1989). "Acesso à Informação nos Arquivos Brasileiros", in Estudos Históricos, vol. 2 (3).

Faria, Carlos A. P. (2012). “O ensino e a pesquisa sobre política externa no campo das relações internacionais do Brasil”, in Austral, vol. 1 (2).

Farias, Rogério de Souza (2011). “O estudo das relações internacionais no Brasil: a crítica da relevância e a relevância da crítica”, in Meridiano 47, vol. 12 (123).

Feldman, L. (2009). "Soberania e modernização no Brasil: pensamento de política externa no segundo reinado e na primeira república", in Contexto Internacional, vol. 31 (3).

Finnemore, M. e Jurkovich, M. (2014). "Getting a Seat at the Table: The Origins of Universal Participation and Modern Multilateral Conferences", in Global Governance, vol. 20 (3).

FonseCa Jr., G. (1989). "Estudo sobre política externa no Brasil: os tempos recentes (1950-1980)", in Fonseca Jr., G. e CarneIro LeÃo, Valdemar Temas de Política Externa Brasileira (Brasília: IPRI). . (2011).Diplomacia e Academia: um estudo sobre as análises acadêmicas sobre a política externa brasileira na década de 70 e sobre as relações entre o Itamaraty e a comunidade acadêmica (Brasília: Funag).

. (2018). "Prefácio", in Lafer, Celso Relações internacionais, política externa e diplomacia brasileira. Pensamento e ação, vol. 1 (Brasília: Funag). 
Franco, Álvaro da C. (2007). Documentos da Política Externa Independente (Brasília: Funag).

Gusmão, Luiz Antônio C. de M. (2012). A produção de teses e dissertações de relações internacionais e áreas afins no Brasil, texto apresentado no $8^{\circ}$ encontro da Associação Brasileira de Ciência Política, Gramado, RS.

- (2016). A publicação de teses do Curso de Altos Estudos do Instituto Rio Branco e o papel do Itamaraty na produção e disseminação do conbecimento sobre relações internacionais no Brasil, texto apresentado no $10^{\circ}$ encontro da Associação Brasileira de Ciência Política, Belo Horizonte, MG.

Herz, M. (2002). "O Crescimento da Área de Relações Internacionais no Brasil”, in Constexto Internacional, vol. 24 (1).

IANNI, O. (1973). "Diplomacia e Imperialismo na América Latina”, in Cadernos CEBRAP, n. 12.

Jaguaribe, H. (2013). O nacionalismo na atualidade brasileira (Brasília: Funag).

Julião, Taís S. (2012). “A Graduação em Relações Internacionais no Brasil”, in Monções, vol. 1 (1).

LAFER, C. (1967). “Uma interpretação do sistema das relações internacionais do Brasil", in Revista Brasileira de Política Internacional, vol. 39-40.

_. (1989/1990). "Diplomacia e transparência: $\mathrm{o}$ arquivo do Itamarati”, in Acervo, vol $4(2) / 5$ (1).

Lake, David A. (2011). "Why 'isms' are evil: theory, epistemology, and academic sects as impediments to understanding and progress", in International Studies Quarterly, vol. 55.

Lessa, Antônio C. (2005). "Instituições, atores e dinâmicas do ensino e da pesquisa em Relações Internacionais no Brasil: o diálogo entre a história, a ciência política e os novos paradigmas de interpretação (dos anos 90 aos nossos dias)", in Revista Brasileira de Política Internacional, vol. 48 (2). - (2014). "Os desafios da publicação em acesso aberto na área de humanidades no Brasil: as estratégias de adaptação da Revista Brasileira de Política Internacional - RBPI", in Boletim Meridiano 47, vol. 15 (146).

Lima, Maria Regina S. e Cheibub, Zairo (1983). Relações Internacionais e Politica Externa Brasileira: debate intelectual e produção acadêmica (Rio de Janeiro: MRE/IUPERJ).

Lima, Maria Regina S. e Milani, Carlos R. S. (2016). "Política externa brasileira: campo de estudo e principais avanços”, in Avritzer, Leonardo; Milani, Carlos R. S.e Braga, Maria do Socorro Sousa $A$ ciência política no Brasil: 1960-2015 (Rio de Janeiro: FGV).

Martins, Carlos Estevam (1977). Capitalismo de Estado e Modelo Político no Brasil (Rio de Janeiro: Graal).

Mello e Silva, A. (1998). "Idéias e política externa: a atuação brasileira na Liga das Nações e na ONU", in Revista Brasileira de Política Internacional, vol. 41 (2).

Miyamoto, S. (1995). Geopolítica e Poder no Brasil (São Paulo: Papirus). 
Gelson Fonseca Junior \& Eduardo Uziel

Notas sobre o campo das relações internacionais no Brasil no centésimo aniversário da disciplina

(1999). “O Estudo das Relações Internacionais no Brasil: o estado da arte", in Revista de Sociologia e Política, vol. 12. . (2003). "O Ensino das Relações Internacionais no Brasil: problemas e perspectivas", in Revista de Sociologia e Política, vol. 20.

Moura, G. (1980).Autonomia na Dependência. A Política Externa Brasileira de 1935 a 1942 (Rio de Janeiro: Nova Fronteira). Nogueira, João P. e Messari, Nizar (2005). Teoria das Relações Internacionais (Rio de Janeiro: Elsevier).

Pecequilo, Critina S. (2017). "Academia versus realidade: estagnação ou solidez?”, in Meridiano 47, vol. 18.

Penna Filho, P. (1999). "A pesquisa histórica no Itamaraty", in Revista Brasileira de Política Internacional, vol. 42 (2).

Pimentel, José Vicente de Sá (2013).Pensamento diplomático brasileiro: formuladores e agentes da política externa (1750-1964) (Brasília: Funag, 3 vols.).

Pinheiro, L. e Vedoveli, P. (2012). "Caminhos Cruzados: Diplomatas e Acadêmicos na Construção do campo de Estudos de Política Externa Brasileira”, in Revista Política Hoje, vol. 21 (1).

Pinheiro, Letícia e Lima, M. R. S. (2018). "Between Autonomy and Dependency: the Place of Agency in Brazilian Foreign Policy", in Brazilian Political Science Review, vol. 12 (3).

Pfrimer, Matheus Hoffmann e OKado, Giovanni Hideki Chinaglia (2019)."Dispersão e concentração espaciais dos cursos de Relações Internacionais no Brasil: contrastes e desafios da expansão da oferta nacional", in Revista Carta Internacional, vol. 14 (1).

Ricupero, R. (2011). "Democracia: princípio e fim da diplomacia”, in Fonseca Jr. G. Diplomacia e Academia: um estudo sobre as análises acadêmicas sobre a política externa brasileira na década de 70 e sobre as relações entre o Itamaraty e a comunidade acadêmica (Brasília: Funag). - (2016). A Diplomacia na construção do Brasil (1750-2016) (Rio de Janeiro: Versal).

Salomón, M. e Pinheiro, L. (2013). “Análise de Política Externa e Política Externa Brasileira: trajetória, desafios e possibilidades de um campo de estudos", in Revista Brasileira de Política Internacional, vol. 56 (1).

SARaiva, José Flávio S. (2012). “Pesquisa em Relações Internacionais no Brasil: Passado, Presente e Perspectivas", in Aguilar, Sérgio L. C. e Albres, Hevellyn M. Relações Internacionais: pesquisa, práticas e perspectivas (Marília: Oficina Universitária).

SeCKInger, R. (1975). "A Guide to Selected Diplomatic Archives of South America", in Latin American Research Review, vol. 10 (1).

Tickner,A. (2008). "Latin American IR and the Primacy of lo práctico", in International Studies Review, vol. 10.

Uziel, Eduardo e Breda dos Santos, N. (2019). "Source Criticism and the History of Brazilian Foreign Policy", in Contexto Internacional, vol. 41 (1).

Vargas, João A. C. (2013). Um mundo que também é nosso: o pensamento e a 
trajetória diplomática de Araujo Castro (Brasília: Funag).

Vigevani, Tullo; Thomaz, Laís F. e Leite, Lucas A. B. (2016). "Pós-Graduação em Relações Internacionais no Brasil. Anotações sobre sua institucionalização", in
Revista Brasileira de Ciências Sociais, vol. 31 (91).

Waisbich, Laura T.; Cetra, Raísa e MARCHEZINI, Joana (2017) .The transparency frontier in Brazilian foreign policy", in Contexto Internacional, vol. 39 (1). 